\title{
Atık Polistiren Matrisli Aerojel Takviyeli Kompozitlerin Üretimi ve Karakterizasyonu
}

\author{
Amin Fiyouj $^{1 *}$, Mevlüt Gürbüz ${ }^{1}$ \\ 1* Ondokuz Mayıs Üniversitesi, Mühendislik Fakültesi, Makina Bölümü, Samsun, Türkiye, (ORCID: 0000-0002-6728-3987), fiuj.amin@yahoo.com \\ ${ }^{2}$ Ondokuz Mayıs Üniversitesi, Mühendislik Fakültesi, Makina Bölümü, Samsun, Türkiye (ORCID: 0000-0003-2365-5918), mgurbuz@omu.edu.tr
}

(1st International Conference on Applied Engineering and Natural Sciences ICAENS 2021, November 1-3, 2021)

(DOI: 10.31590 /ejosat.1011779)

ATIF/REFERENCE: Fiyouj, A. \& Gürbüz, M. (2021). Atık Polistiren Matrisli Aerojel Takviyeli Kompozitlerin Üretimi ve Karakterizasyonu. Avrupa Bilim ve Teknoloji Dergisi, (28), 869-872.

$\ddot{O} \mathbf{z}$

Bu çalışmada atık strafordan elde edilen polistiren matris malzeme, takviye olarak da ağıllıkça farklı oranlarda aerojel (ağ.\% 3, 6 ve 9) kullanılarak kompozitler üretilmiştir. Elde edilen kompozitlere çekme dayanımı ve Shore sertlik testleri ugulanmıştır. Kompozitlerin mikroyapıları taramalı elektron mikroskobu (SEM) ile analiz edilmiştir. Sonuçlardan polistiren maksimum çekme dayanımı $0.67 \mathrm{MPa}$ ve shore sertlik değeri 162 olurken, Aerojel takviyeli kompozitlerde ise ağ.9\% aerojel içeren kompozit $0.85 \mathrm{MPa}$ maksimum çekme dayanımı göstermiş, Shore sertliği ise 202'ye kadar arttığı görülmüştür.

Anahtar Kelimeler: Polistiren, aerojel, çekme, shore sertliği

\section{Fabrication and Characterization of Aerogel Reinforced Polystyrene Matrix Composites}

\begin{abstract}
In this study, polystyrene obtained from waste styrofoam, aerogel (3, 6 and 9 wt.\%) were used as matrix and reinforcement elements to fabricate composites. Tensile strength, Shore hardness test were applied to the obtained composites. The microstructures of the composites were analyzed by scanning electron microscopy (SEM). From the results, the maximum tensile strength of polystyrene was $0.67 \mathrm{MPa}$ and the shore hardness value was 162 , while the composite containing $9 \% \mathrm{wt}$ of airgel showed a maximum tensile strength of $0.85 \mathrm{MPa}$, and the Shore hardness increased up to 202 .
\end{abstract}

Keywords: Polystyrene, aerogel, tensile, shore hardness.

\footnotetext{
* Sorumlu Yazar: fiuj.amin@yahoo.com
} 


\section{Giriş}

sektörlerde kendine yer açan ve neredeyse tüm ekonomik ve sanayi faaliyetlerine girmiş bir alandır[1]. Kompozit üretiminde kullanılan matris malzemelerden biride polisitiren matris kompozitlerdir. Bu kompozitler korozyon direncini artırmada, kil teknolojilerinde, farklı uygulamalar için su tutmaz yüzeyler, yanmazlık, 1s1/ses yalıtımı, mekanik özellik vb. film kompozit formunda yaygın olarak kullanılmaktadır[2]. Kompozit malzemelerin savunma sanayi, tekstil, uçak, denizcilik ve otomotiv sektöründe kullanımının önemli yeri vardır[3]. Aerojel 1960'lardan beri uzay yolculuğunda kullanılan, ancak şu anda tüm endüstrilerde kullanım alanı bulan olağanüstü bir malzeme grubundan bahsetmek için kullanılan geniş bir terimdir. Aerojel teknik olarak bir köpük olmasına rağmen, birçok farklı şekil ve formda olabilir. Aerojelin çoğunluğu silikadan oluşur, ancak karbon, demir oksit, organik polimerler, yarı iletken nano yapılar, altın ve bakır da aerojel oluşturabilir [4].

Dünyada en iyi 1sı yalıtımı sağlayan birkaç malzemeden biri olan EPS, performans/fiyat analizi yapıldığında diğer isı yalıtım malzemelerine göre ekonomik çözümler sağlayan bir yap1 malzemesidir. $\mathrm{Bu}$ yapı malzemelerinin kullanım sonrasında birçok atık oluşmakta bu da çok fazla geri dönüşüm olarak değerlendirilmemektedir.

$\mathrm{Bu}$ nedenle bu çalışmada, inşaat atıklarından elde edilen ucuz üretim yöntemi ve pahalı hammaddelere alternatif polisitiren kaynağ1 olarak atık strafor köpüklerin geri dönüşümü ile mekanik özelliği ve aerojellerin kullanılmasıyla geliştirilmesi amaçlanmıştır.

\section{Materyal ve Metot}

Bu çalışmada, matris malzemesi olarak inşaat atıklarından toplanan strafor polistiren (Ps) matris olarak ve takviye malzemesi olarak farklı oranlarda silika esaslı aerojel kullanılmıştır. Strafordan polistiren elde etmek için çözücü olarak asetilaseton kullanılmıştır.

Şekil 1'de akış diyagramı verilen çalışmada atık strafor, asetilasetonda çözündürülerek matris olarak kullanılmıştır. Takviye elemanı olarak ise aerojel farklı oranlarda (ağ.\% 3, 6, 9 ) kullanılmıştır. Straforun polisitiren kaynağı olarak çözünme sonrası takviyelenmiş, sonrasında gözenek yapmaması için vakumdan geçirilerek kalıba döküm sonrası kompozitler üretilmiştir. Üretilen kompozitlerden test numunesi olarak hazırlanarak, mekanik özellik olarak shore sertliği ve çekme testi yapılmıştır. Üretilen kompozitlerin mikroyapısı taramalı elektron mikroskobu (SEM) ile analiz edilmiştir.

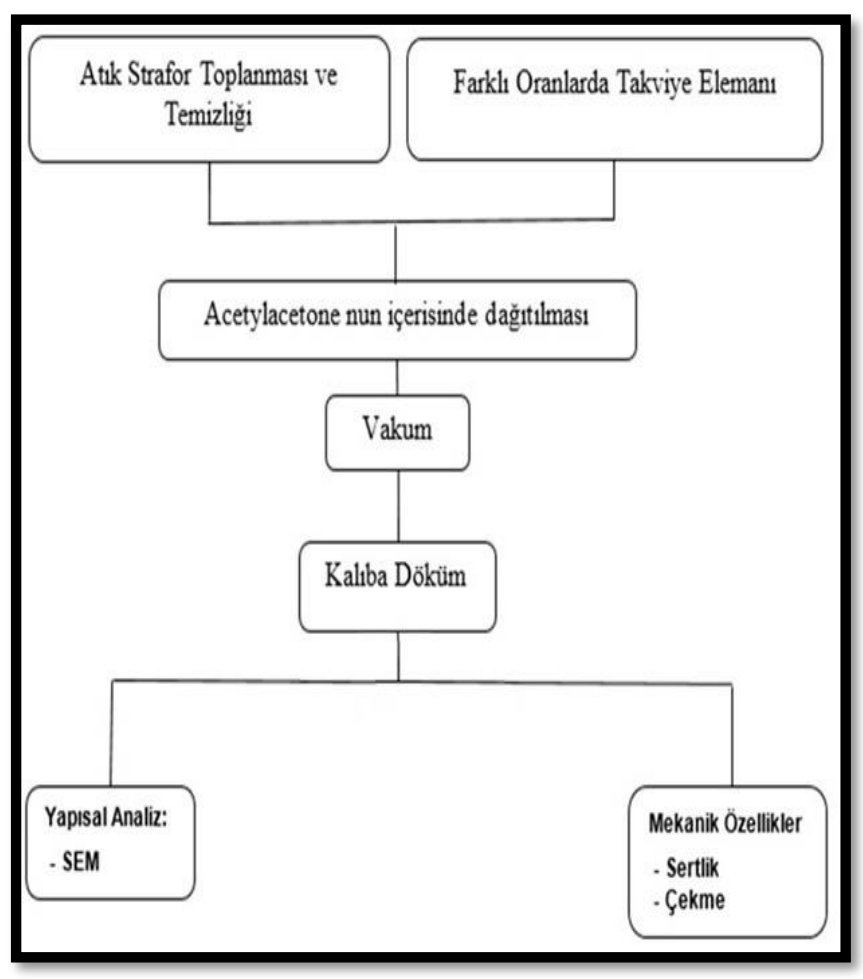

Şekil 1. Aerojel takviyeli Ps kompozit üretim aşamaları

Numune hazırlamak için ilk olarak inşaat atığı olan blok strafor ürünler küçük boncuklar şeklinde parçalanmıştır. Daha sonra asetilaseton içerisinde çözündürülmüş, çözündürme işlemi sonrası kompozit reçetesıne göre takviye elemanları eklenmiş, çözünme ve karıştırma işleminden oluşan hava kabarcığ vakuma alınarak kalıba dökülecek kıvama getirilmiştir. Kalıba dökülebilir numune hazırlandıktan sonra kalıp tasarımı yapılmış ve dökülerek kalın plaka formunda örnekler hazırlanmıştır.

Kalıpları hazırlamak için $250 \times 70 \times 20 \mathrm{~mm}$ cam kullanılmıştır. Sonraki aşamada gerek takviyesiz gerekse farklı oranlarda aerojel takviyeli yapılar üretilen kalıplara dökülmüş ve kurumaya bırakılımıştır. Kuruma sonrası örnekler yapılacak teste göre kesilerek test örnekleri hazırlanmıştır (Şekil 2).

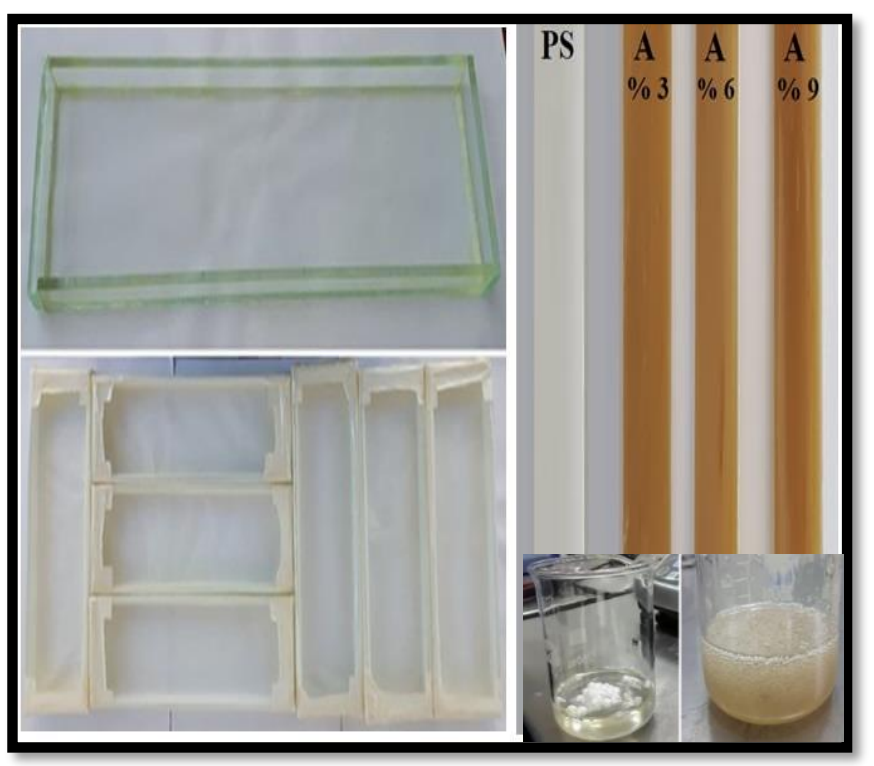

Şekil 2. Kalıp tasarımı ve polistiren-aerojel takviyeli kompozitlerin çekme örnekleri 


\section{Araştırma Sonuçları ve Tartışma}

\subsection{Numunelerin Çekme Testi}

Üretilen örnekler çekme cihazına bağlanmıș $1 \mathrm{~mm} / \mathrm{dk}$ çekme hızında testler yapılmış, cihazdan alınan datalar ile çekme dayanımı birim uzama eğrileri çizilmiştir.

Şekil 3'de gerilme birim uzama eğrisinden verildiği üzere takviyesiz Ps örneklerin mekanik özelliği 0.67 MPa maksimum dayanım gösterirken, çalışmada farklı oranlarda aerojel (ă̆.\% 39 arası) çalışılmış ve en yüksek mekanik özellik ağ. $9 \%$ aerojel içeren de $0.85 \mathrm{MPa}$ tespit edilmiştir. Bu değerin üzerinde proses esnasında aşırı topaklanma olduğu için örnek hazırlanamamıştır.

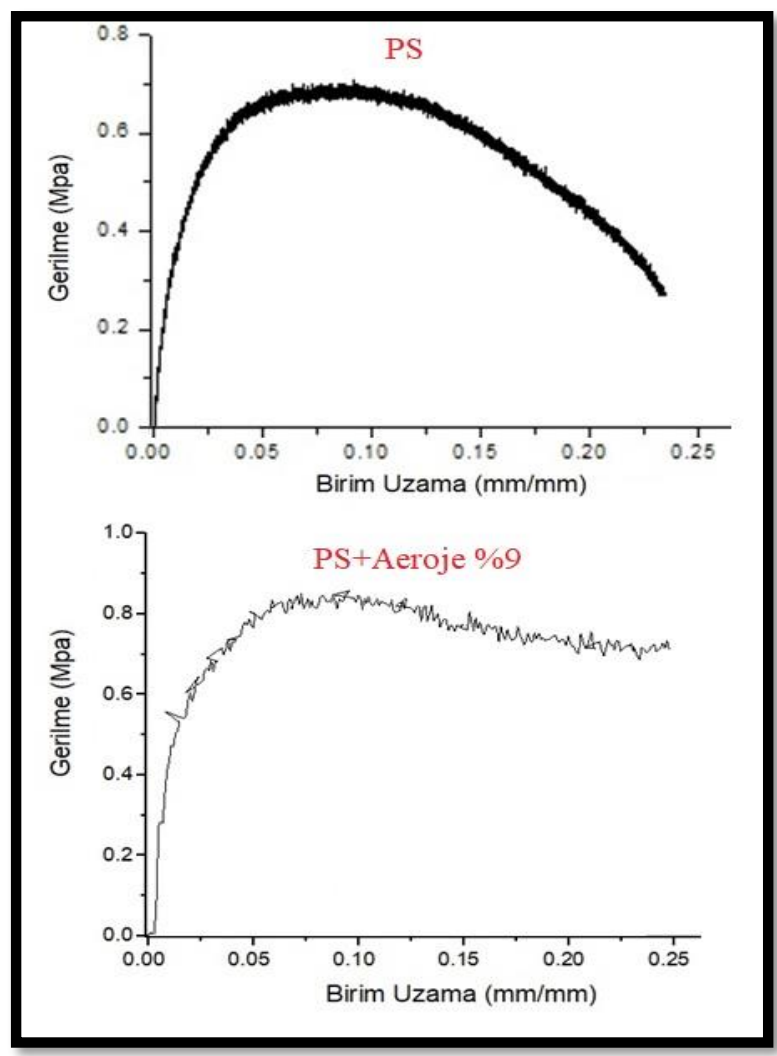

Şekil 3. Ps ve Aerojel takviyeli kompozitlerin çekme eğrisi

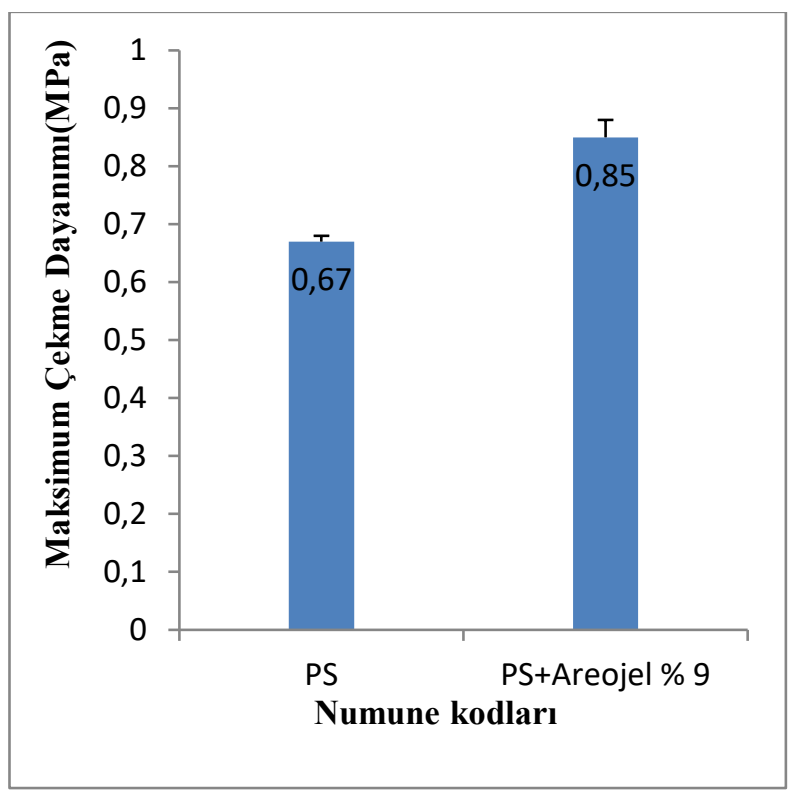

Şekil 4. Ps ve Aerojel takviyeli kompozitlerin ortalama maksimum çekme dayanımları

\subsection{Numunelerin Shore Testi}

Üretilen kompozitlerin $(10 \mathrm{~mm} \times 10 \mathrm{~mm})$ sertlik davranışı ise Shore sertlik testi ile yapılmıştır. Sertlik sonuçlarından görüldüğü üzere polistiren sertlik değeri 162 tespit edilirken, aerojel ilavesi ile bu değerde ciddi bir artış olup ve ağ. \%9 aerojel takviyeli Ps kompozit için sertlik 202 olarak bulunmuştur.

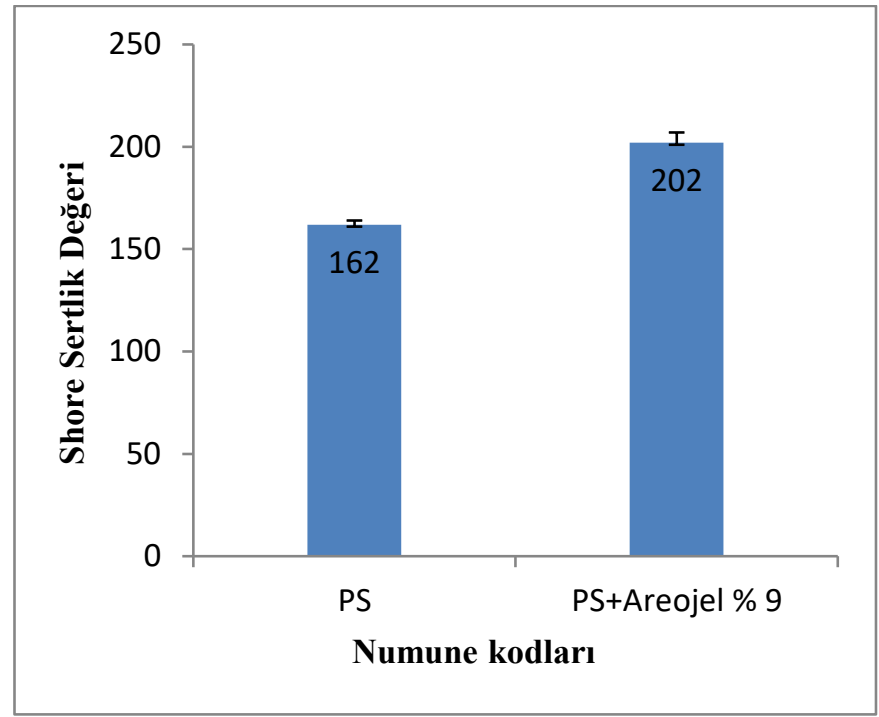

Şekil 5. Ps ve Aerojel takviyeli kompozitlerin ortalama shore sertlik değerleri

\subsection{Numunelerin SEM ve EDX harita görüntüsü}

Şekil 5.6a-c'de takviyesiz Ps ve aerojel takviyeli Ps kompozitlerin düşük ve yüksek büyütmeli SEM görüntülerinden görüldüğü üzere aerojel partikülleri yapıda gözükmektedir. A ğ.\%9 aerojel içeren Ps kompozitin EDX harita analizinden görüldüğü üzere aerojel partiküller yapıda homojen olarak dağılmıştır. Yeşil ve mavi renkli bölgeler Si ve O, kırımızı renkli bölgeler ise Ps'den gelen C'a aittir.
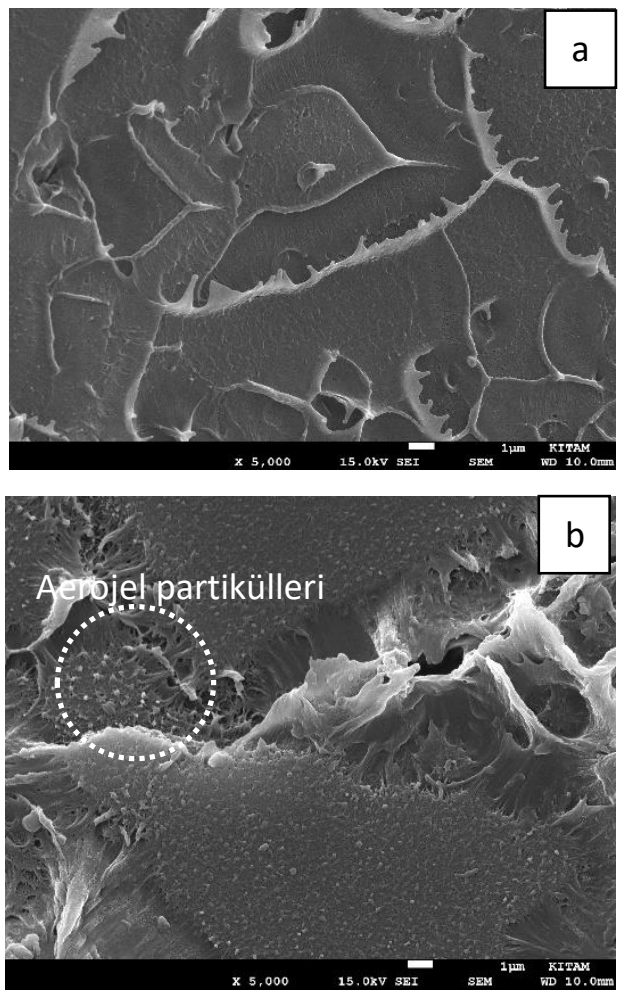


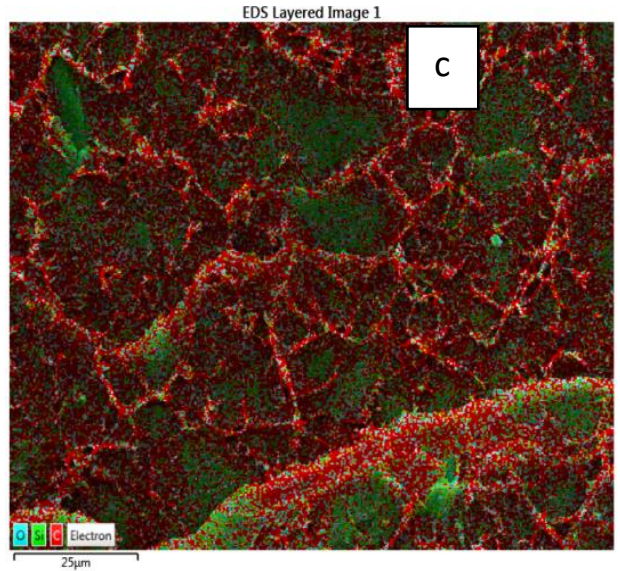

Şekil 6. Ps ve aerojel takviyeli kompozitlerin SEM (a-b) ve EDX harita analizi (c)

\subsection{Tartışma}

Partikül takviyeli kompozit yapılarda partikülün yapı içinde homojen dağıtılması oldukça önemlidir. Belli bir değere kadar tozlar matris içinde homojen dağılım gösterirken optimum değerin üzerinde partiküller arasındaki elektrostatik çekimden dolayı topaklanmaktadır. Bu topaklar kompozit içerisinde lokal olarak heterojen dağılmakta ve gözenek oluşturmaktadır. Ayrıca bu topaklardan kaynaklanan zayıf arayüz etkileşimi meydana gelmektedir. Bunların sonucunda mekanik özellikler olumsuz etkilenmektedir. Bu çalışmada kompozit yapılarda aerojel belli bir değere kadar (bu çalışmada ağ.\% 9) yapıda homojen dağılımdan dolayı güçlendirici etki yapmıştır. Maksimum çekme dayanımı ve sertlik sonuçlarından görüldüğü üzere aerojel ilavesi arttıkça mekanik özellik polistiren sisteme göre daha da artmıştır. Bunun nedeni polistiren sistemde test esnasında polistiren arayüz arasına aerejel yapıları girerek yük altında arayüz deformasyonu daha zor olmaktadır. Burada da aerojel katkısı polisitiren-aerojel arayüzünde test anında kaymaya karşı zorlanma etkisi yaratmaktadır. Aerojelin varlığında ortaya çıkan sürtünmeden dolayı test esnasında bu sürtünmeyi yenmek için daha fazla yük altında deformasyon gerçekleşmektedir. Ayrıca, artan aerojel miktarıyla sertlikte artış olması ise aerojelin seramik esaslı ve Ps'e göre daha sert malzeme olması ve partiküller arasındaki arayüz bağlantısının güçlü olması verilebilir [5-7].

\section{Sonuç}

$\mathrm{Bu}$ çalışmada Ps matris kaynağı olarak atık strafor kullanılmış, elde edilen Ps matrise takviye olarak ağırlıķa farklı oranlarda aerojel (ağ.\% 3, 6 ve 9) kullanılarak kompozitler üretilmiştir. Sonuçlardan takviyesiz polistiren maksimum çekme dayanımı 0.67 MPa ve shore sertlik değeri 162 olurken, aerojel takviyeli kompozitlerde ise ağ.9\% aerojel içeren kompozit için $0.85 \mathrm{MPa}$ maksimum çekme dayanımı göstermiş, Shore sertliği ise 202'ye kadar arttığı görülmüştür.

\section{Kaynakça}

[1] O. Arıcasoy.,. İstanbul Ticaret Odası. İstanbul Ticaret Odası Kompozit Sektör Raporu. Aralık, 2006

[2] B. Beşergil, Kompozitler. Gazi Kitabevi. 2016, Türkiye

[3] F. Yastımoğlua, A. Özkan, 2017. “Tekrarlanan yükler altında kompozit malzemelerin yapılarının incelenmesini amaçlayan deney aygıtı tasarımı", Düzce Üniversitesi Bilim ve Teknoloji Dergisi, 5 (2017) 56-66

[4] G.P. Thomas, "What is Aerojel? Theory, Properties and Applications”, Azo Materıals. Aug. 22, 2012

[5] K.G. Dassios, "A Review of the Pull-Out Mechanism in the Fracture of Brittle-Matrix Fibre-Reinforced Cowosites" Advanced Composites Letters (2007) 161(1)

[6] M.C. Şenel, M. Gürbüz, "Investıgatıon on Mechanıcal Properties and Microstructures of Aluminum Hybrid Composites Reinforced with $\mathrm{Al}_{2} \mathrm{O}_{3} /$ GNPs Binary Particles. Arch. Metall. Mater. 66 (2021), 1, 97-106

[7] M.C. Şenel, M. Gürbüz, "Synergistic effect of graphene/boron nitride binary nanoparticles on aluminum hybrid composite properties". Advanced Composites and Hybrid Materials (2021) 